\title{
Different lung responses to cigarette smoke in two strains of mice sensitive to oxidants
}

\author{
B. Bartalesi, E. Cavarra, S. Fineschi, M. Lucattelli, B. Lunghi, P.A. Martorana and G. Lungarella
}

ABSTRACT: The development of cigarette smoke-induced pulmonary changes in $\mathrm{C} 57 \mathrm{BI} / 6 \mathrm{~J}$ and $\mathrm{DBA} / 2$ mice was investigated. Both strains are sensitive to oxidants and $\mathrm{C57BI/6J}$ mice are moderately deficient in serum alpha1-proteinase inhibitor.

Following chronic exposure to cigarette smoke, patchy emphysema was present in mice of both strains, but developed faster in DBA/2 mice. A positive reaction for mouse neutrophil elastase was seen on the septa of both strains. Additionally, the DBA/2 mice developed a uniform parenchymal dilation that was preceded by the appearance of apoptotic cells in areas with a low signal for vascular endothelial growth factor-receptor 2. Fibrotic areas scattered throughout the parenchyma, coupled with a positive immunohistochemical reaction for transforming growth factor- $\beta$ was seen only in DBA/2 mice.

Both $\mathrm{DBA} / 2$ and $\mathrm{C57BI} / 6 \mathrm{~J}$ strains showed epithelial cell injury and areas of deciliation in their airways. However, the appearance of goblet cell metaplasia was common in $\mathrm{C57BI} / 6 \mathrm{~J}$ mice but rare in DBA/2 mice. A positive immunohistochemical reaction for interleukin (IL)-4, IL-13 and MUC5AC was seen only in the airways of $\mathrm{C57BI} / 6 \mathrm{~J}$ mice.

Strain characteristics (alpha1-proteinase inhibitor levels, sensitivity to oxidants, and constitutive levels of vascular endothelial growth factor-receptor 2) and phenotypical responses (apoptosis and cytokine distribution) may condition parenchymal and airway changes to cigarette smoke.

KEYWORDS: Bronchial changes, emphysema, expression of cytokines, mouse interstrain variations

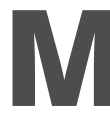
orbidity and mortality from chronic obstructive pulmonary disease (COPD) is a health problem of global dimension and cigarette smoke has been identified as the most important risk for the development of COPD $[1,2]$. However, it is well recognised that in a population of heavy smokers only $15-20 \%$ of subjects develop COPD [3]. The reason for this is unknown; however, it is likely that individual genetic risk factors may play an important role [4, 5].

Mice of an inbred strain are genetically identical, thus mice from different strains represent an ideal model for investigating the susceptibility of different phenotypes in developing cigarette smoke-induced lesions.

In a previous study, the present authors investigated the effects of acute and chronic exposure to cigarette smoke in three different inbred strains of mice, namely ICR, DBA/2 and C57Bl/6J. When acutely exposed to cigarette smoke, ICR strain mice significantly increased the antioxidant capacity in their bronchoalveolar lavage fluid
(BALF). In contrast, mice of the strains DBA/2 and $\mathrm{C} 57 \mathrm{Bl} / 6 \mathrm{~J}$ showed a significant drop of the antioxidant capacity in their BALF. Also, while ICR and DBA/2 mice have constitutively normal levels of elastase inhibitory capacity (EIC) in BALF samples, C57Bl/6J mice have significantly lower levels $(-40 \%$ with respect to the other strains) [6].

When exposed chronically (7 months) to cigarette smoke, ICR strain mice did not show a drop in lung elastin content and did not develop emphysema. In contrast, lung elastin content was significantly decreased in C57Bl/6J and DBA/2 mice that developed significant emphysema [6].

In the present study, the differences that characterise the development of cigarette smokeinduced parenchymal lesions were investigated, as well as airway changes in two susceptible strains: C57Bl/6J and DBA/2. The present study was carried out in an attempt to associate the development of cigarette smoke-induced lesions to certain phenotypical responses characteristic of a mouse strain.
AFFILIATIONS

Dipartimento di Fisiopatologia e Medicina Sperimentale, Università di Siena, Siena, Italy.

CORRESPONDENCE

G. Lungarella

Dipartimento di Fisiopatologia e

Medicina Sperimentale

Università di Siena

Via Aldo Moro n.6

I-53100 Siena

Italy

Fax: 390577234019

E-mail: lungarella@unisi.it

Received

June 072004

Accepted after revision:

August 132004

\section{SUPPORT STATEMENT}

This work was supported by a grant from the Ministero dell'Istruzione, dell'Università e della Ricerca (Rome, Italy) and by a grant from University of Siena (Piano di Ateneo per la Ricerca, Progetti, Italy). 


\section{METHODS}

\section{Animals}

Male mice aged 2 months of the strains C57Bl/6J and DBA/2 (Charles River, Calco, Italy) were used. All animal experimentation was approved by the Local Ethical Committee of the University of Siena, Siena, Italy.

\section{Chronic exposure to cigarette smoke}

The methodology for chronic smoke exposure has been previously described in detail [6]. Briefly, mice of the strains $\mathrm{C} 57 \mathrm{Bl} / 6 \mathrm{~J}$ and $\mathrm{DBA} / 2$ were exposed to either the smoke of 3 cigarettes $\cdot$ day $^{-1}$ (commercial Virginia filter cigarettes: $12 \mathrm{mg}$ of tar and $0.9 \mathrm{mg}$ of nicotine), 5 days $^{*}$ week $^{-1}$ for $1,3,6$ and 10 months or to room air (controls), in specially designed macrolon cages (Tecniplast, Buguggiate, Italy).

\section{Light microscopy: morphology, morphometry, immunohistochemistry and the tunel test}

At various time intervals during the chronic exposure to room air or cigarette smoke, groups of animals of both strains were anaesthetised with ether and then exsanguinated by severing the abdominal aorta. The lungs were excised and fixed intratracheally with buffered formalin (5\%) at a constant pressure of $20 \mathrm{~cm} \mathrm{H} \mathrm{H}_{2} \mathrm{O}$ for $\geqslant 24 \mathrm{~h}$. Post-fixation lung volume was measured by water displacement. The lungs of all animals were then processed for histological examination and stained with haematoxylin-eosin and/or periodic acid-Schiff (PAS). The lungs of the mice of both strains sacrificed at 6 and 10 months were also stained with Masson's trichrome.

\section{Emphysema}

Morphometric assessment of emphysema, performed in all animals, included determination of the average inter-alveolar distance (mean linear intercept: Lm) [7] and internal surface area (ISA) estimated by the Lm method at post-fixation lung volume [8].

\section{Fibrosis}

Morphometric evaluation of fibrosis, performed in all animals at 6 and 10 months, consisted of the determination of the per cent volume density of fibrosis, by point counting. Point counting was performed by determining 20 random fields per slide and using a multipurpose grid to count 45 points per field for a total of 900 points for each slide. Fibrosis was defined as inflammatory cell infiltration within the alveolar septa and alveolar spaces with deposition of extracellular matrix [9].

\section{Goblet cell metaplasia}

Since mice do not have goblet cells in their bronchi [10], a mouse was considered to have goblet cell metaplasia (GCM) when at least one or more middle size bronchi/lung showed a positive PAS staining.

\section{Immunohistochemistry}

Tissue sections ( $8 \mu \mathrm{m}$ thick) from mice of both strains were stained for transforming growth factor (TGF)- $\beta$, interleukin (IL)-4, IL-13, MUC5AC (all at 3 and 6 months), neutrophil elastase, vascular endothelial growth factor (VEGF) and VEGFreceptor 2 (R2) (last three at 1 and 3 months) by an immunoperoxidase method.
The primary polyclonal antibodies $(\mathrm{Ab})$ used were: rabbit $\mathrm{Ab}$ to mouse TGF- $\beta$ (Insight Biotechnology LTD., Wembley, UK), goat $\mathrm{Ab}$ to mouse IL-4 or MUC 5AC, rabbit $\mathrm{Ab}$ to mouse VEGF or VEGF-R2 (Santa Cruz Biotechnology, Inc., Santa Cruz, CA, USA), goat $\mathrm{Ab}$ to mouse IL-13 (R\&D Systems Inc., Minneapolis, MN, USA), rabbit $\mathrm{Ab}$ to human neutrophil elastase (cross-reacting with mouse neutrophil elastase) diluted 1:500 (Calbiochem-Novabiochem, San Diego, CA, USA). As negative controls for the immunostaining, the primary $\mathrm{Ab}$ was replaced by nonimmunised rabbit or goat serum. The sections were counterstained with haematoxylin.

\section{The Tunel test}

For the Tunel test, paraffin-embedded lung sections from both strains at 1 and 3 months were used. The test was carried out according to a commercially available kit (In Situ Cell Death Detection Kit, Fluorescein; Roche Diagnostic GmbH, Mannheim, Germany).

\section{Transmission electron microscopy}

After 3 months of exposure, the lungs of some animals of both strains were processed for transmission electron microscopy and examined in a Philips 300 electron microscope (Philips Electron Optics, Eindhoven, the Netherlands) as previously described [11]

\section{Statistical analysis}

The significance of the mean differences was calculated using one-way ANOVA (F-test). A p-value of $<0.05$ was considered significant.

\section{RESULTS}

\section{Parenchymal changes}

Two types of lesions affecting the parenchyma at various degrees were seen in the cigarette smoking mice of both strains, namely emphysema and fibrosis. However, there were clear differences in the morphology of these two pathologies between the strains.

With regard to the quantification of emphysema the data of the Lm and of the ISA obtained in both strains after 1, 3, 6 and 10 months exposure either to room air or to cigarette smoke are presented in table 1 .

After 1 month of cigarette smoke exposure neither the DBA/2 nor the $\mathrm{C} 57 \mathrm{Bl} / 6 \mathrm{~J}$ mice had Lm and ISA mean values different from those of the respective controls. However, one out of five DBA/2 mice showed overt emphysema and two out of five showed some spotty emphysematous lesions. After 3 months of smoke exposure the DBA/2 mice had overt emphysema characterised by significant changes to both the Lm and the ISA.

At this time point, the C57B1/6J mice showed a statistical increase of the Lm. However, no decrease of the ISA was seen, indicating that in this strain the destructive changes were not yet fully developed. In an attempt to investigate the mechanism(s) of action of the development of emphysema in these two strains, the immunohistochemical investigation of neutrophil elastase, VEGF and VEGF-R2 as well the Tunel test were carried out at 1 and 3 months after the beginning of the exposure, i.e. at the time when emphysema develops. Immunohistochemical examination, carried out at 3 months, 
TABLE 1 Morphometric parameters of the lungs of $\mathrm{C} 57 \mathrm{BI} / 6 \mathrm{~J}$ and DBA/2 mice determined at various time intervals during chronic exposure to either room air or cigarette smoke

\begin{tabular}{lccc} 
Group & Exposure time months & Lm $\mu \mathbf{m}$ & ISA cm $^{\mathbf{2}}$ \\
\hline C57BI/6J: A & 1 & $35.74 \pm 0.66(5)$ & $1121 \pm 20(5)$ \\
C57BI/6J: S & 1 & $36.02 \pm 1.22(5)$ & $1116 \pm 37(5)$ \\
DBA/2: A & 1 & $36.95 \pm 0.36(5)$ & $1200 \pm 31(5)$ \\
DBA/2: S & 1 & $36.01 \pm 4.02(5)$ & $1191 \pm 31(5)$ \\
C57BI/6J: A & 3 & $35.45 \pm 0.88(8)$ & $1266 \pm 68(8)$ \\
C57BI/6J: S & 3 & $39.19 \pm 0.80^{\star *}(16)$ & $1229 \pm 43(16)$ \\
DBA/2: A & 3 & $36.77 \pm 0.34(4)$ & $1110 \pm 29(4)$ \\
DBA/2: S & 3 & $43.72 \pm 0.52^{\star *}(6)$ & $935 \pm 41^{\star *}(6)$ \\
C57BI/6J: A & 6 & $40.50 \pm 0.88(8)$ & $1209 \pm 10(8)$ \\
C57BI/6J: S & 6 & $47.69 \pm 0.94^{\star *}(14)$ & $1059 \pm 24^{\star *}(14)$ \\
DBA/2: A & 6 & $37.17 \pm 0.34(7)$ & $1269 \pm 31(7)$ \\
DBA/2: S & 6 & $45.12 \pm 1.11^{* *}(10)$ & $1176 \pm 25^{\star *}(10)$ \\
C57BI/6J: A & 10 & $41.33 \pm 0.51(8)$ & $1113 \pm 45(7)$ \\
C57BI/6J: S & 10 & $45.64 \pm 0.89^{\star *}(10)$ & $989 \pm 30^{\star *}(9)$ \\
DBA/2: A & 10 & $37.58 \pm 0.39(7)$ & $1292 \pm 31(7)$ \\
DBA/2: S & 10 & $46.55 \pm 0.69^{\star *}(8)$ & $1097 \pm 43^{\star *}(8)$ \\
\hline
\end{tabular}

Data are given as mean \pm SEM (number of animals). Lm: linear intercept; ISA: internal surface area of the lung; A: exposed to air; S: exposed to cigarette smoke. **: $p<0.01$ versus the respective group exposed to air

revealed a positive reaction for mouse neutrophil elastase on the septa of both DBA/2 and C57Bl/6J mice (fig. 1a and b).

A differing degree of apoptosis was found between DBA/2 and $\mathrm{C} 57 \mathrm{Bl} / 6 \mathrm{~J}$ at 1 and 3 months after cigarette smoke exposure (fig. 2). In particular, DBA/2 mice showed a large number of apoptotic cells uniformly distributed in the parenchyma at 1 month after smoking (fig. 2a). At 3 months, the level of apoptosis in these mice was markedly decreased (fig. 2b). In contrast, no apoptotic cells were seen in C57Bl/6J at 1 month after smoking, whilst at 3 months a mild apoptosis was seen in these mice (fig. 2c and $\mathrm{d}$ ).
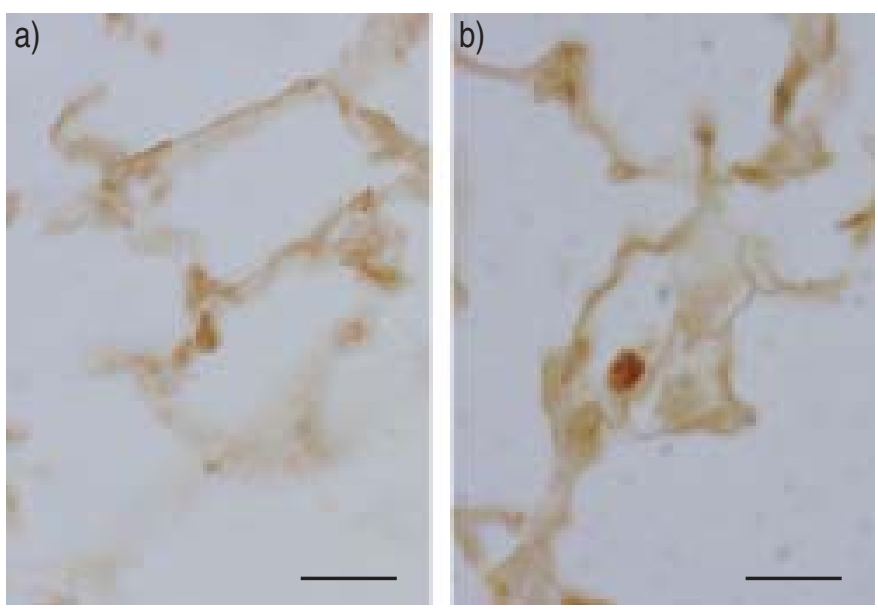

FIGURE 1. Immunohistochemical reaction for neutrophil elastase on the alveolar septa of a) DBA/2 mice and b) C57BI/6J mice, 3 months after cigarette smoke exposure. Scale bar $=28 \mu \mathrm{m}$.
The immunohistochemical reactions for VEGF-R2 in DBA/2 and $\mathrm{C} 57 \mathrm{Bl} / 6 \mathrm{~J}$ control mice are shown in figure $3 \mathrm{a}$ and $\mathrm{d}$. $\mathrm{C} 57 \mathrm{Bl} / 6 \mathrm{~J}$ mice had a marked reaction diffuse throughout the parenchyma whilst surprisingly, the DBA/2 mice did not show any reaction. After cigarette smoke exposure, C57Bl/6J mice showed at 1 and 3 months a progressive decrement of the immunological reaction (fig. $3 e$ and f). In contrast, in DBA/2 mice a trivial to mild immunological signal was seen at 1 and 3 months after cigarette smoke, respectively (fig. $3 b$ and c).

With regards to the immunohistochemistry of VEGF, no differences were seen among the controls as well as the experimental groups of the two strains at 1 and 3 months after cigarette smoke (data not shown).

After 6 months of cigarette smoke exposure, emphysema was overt in both strains. In the $\mathrm{C} 57 \mathrm{Bl} / 6 \mathrm{~J}$ mice the lesion was characterised by disseminated foci of severe emphysema interspersed by apparently normal parenchyma (fig. 4d). In DBA/2 mice foci of emphysema were scattered in what appeared to be a uniformly dilated parenchymal network (fig. 4b). In both strains at this time point there were significant changes of the Lm and ISA.

There were no further increments of these two parameters after 10 months of cigarette smoke indicating a certain stabilisation of the emphysematous lesion.

Foci of fibrosis were seen from 6 months of smoke exposure onwards in the mice of both strains, but their severity and distribution were different in the two strains. In the DBA/2 mice, the fibrotic lesions consisted mainly of subpleural foci (fig. 5a). Occasionally, some areas of fibrotic reaction were seen interspersed in the lung parenchyma. These areas were sometimes associated with foci of emphysema. Volume density 

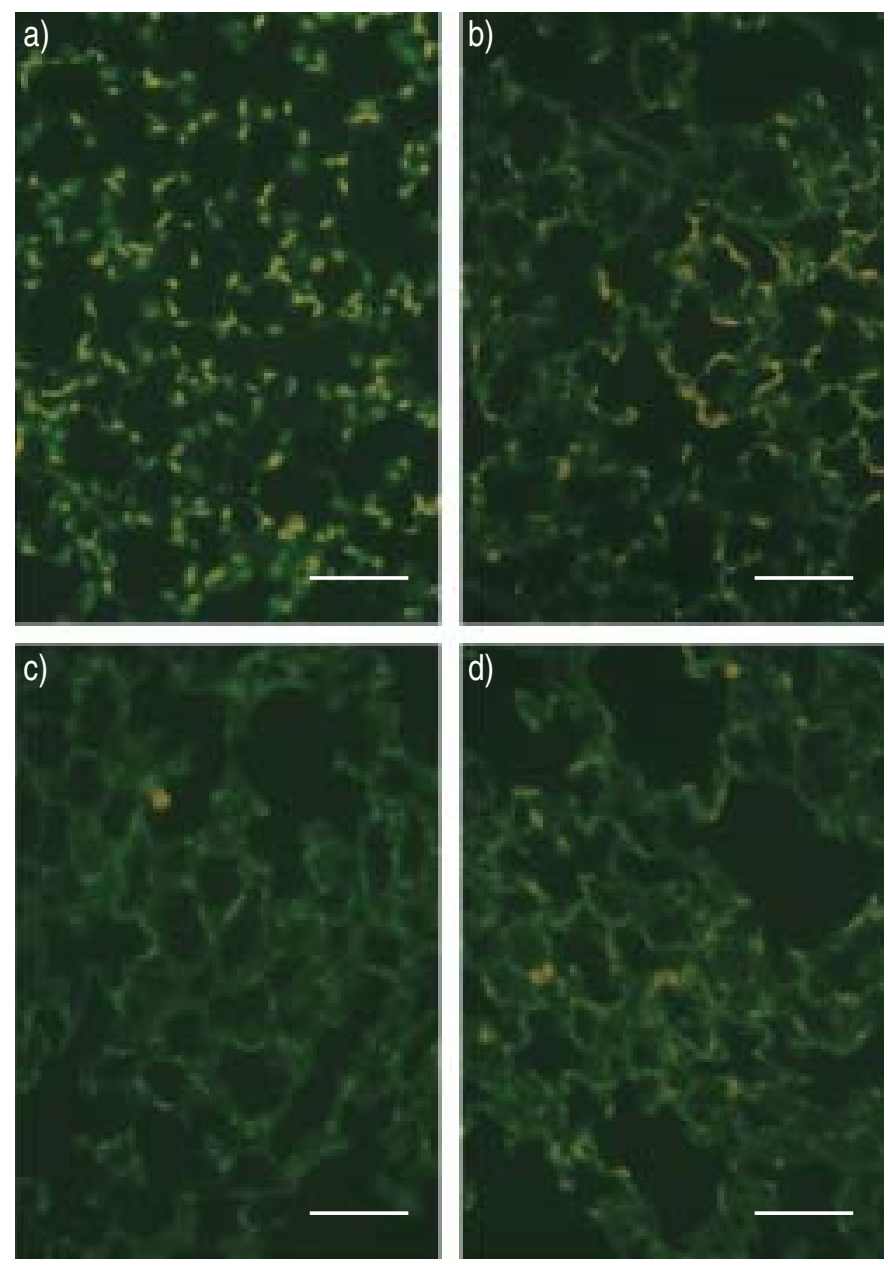

FIGURE 2. Apoptotic cells in the lung of DBA/2 mice at a) 1 month and b) 3 months after cigarette smoking. Apoptotic cells in the lung of C57BI/6J mice at c) 1 month and d) 3 months after smoke exposure. Pictures obtained using the Tunel test with fluorescent microscopy. Scale bar $=111 \mu \mathrm{m}$.

of fibrosis in this strain was $5.2 \pm 1.4 \%$ and $4.8 \pm 1.6 \%$ at 6 and 10 months, respectively. Both these data were significantly different $(p<0.05)$ from the respective controls that did not have fibrosis $(0 \%)$. Either no fibrosis or trivial foci of fibrosis were seen in $\mathrm{C} 57 \mathrm{Bl} / 6 \mathrm{~J}$ mice. In this strain volume density of fibrosis was $0.6 \pm 0.2 \%$ and $0.7 \pm 0.2 \%$ at 6 and 10 months, respectively. Both these values were significantly higher than those of the respective controls $(0 \%)$ but significantly lower than those of the DBA/2 mice at the same time points. In both strains these changes were characterised by a positive immmunohistochemical reaction for TGF- $\beta$; however, while this reaction was marked in DBA/2 mice (fig. $5 b$ ) it was only faint in $\mathrm{C} 57 \mathrm{Bl} / 6 \mathrm{~J}$ mice.

\section{Airway changes}

There was a striking difference between the two strains with regard to the development of GCM after exposure to cigarette smoke. In the C57Bl/6J groups two out of five (40\%) animals showed a positive PAS reaction of their large or middle size bronchi at 1 month, 12 out of 16 (75\%) at 3 months (fig. 6), 11 out of $14(78 \%)$ at 6 months and seven out of $10(70 \%)$ at 10 months. In the DBA/2 groups there were no PAS-positive
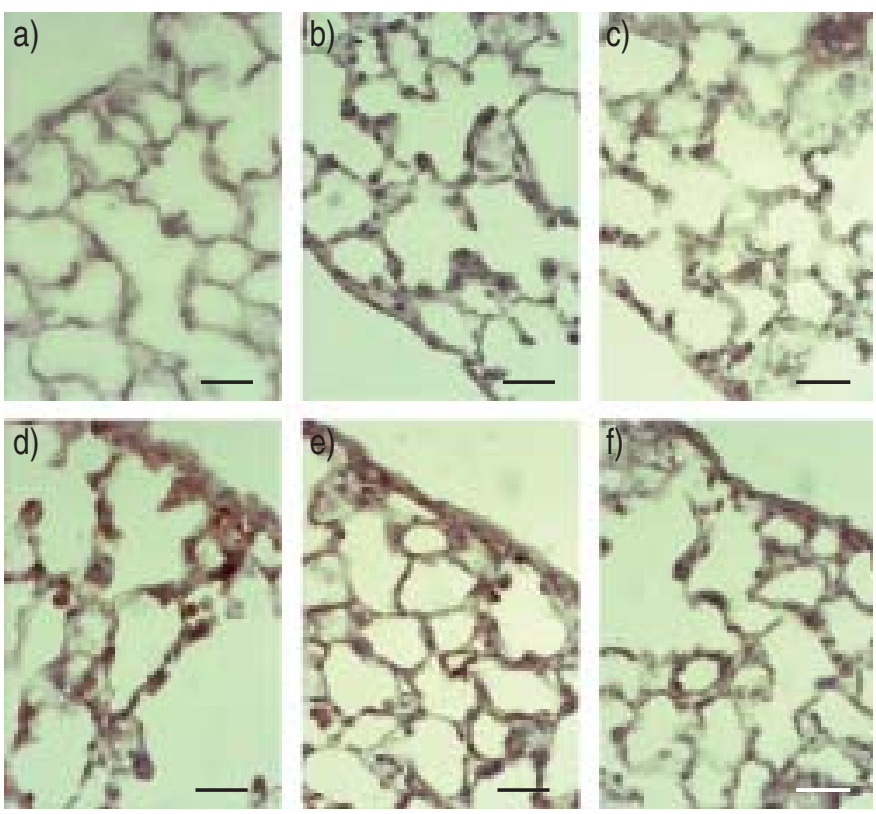

FIGURE 3. Immunohistochemical reaction for vascular endothelial growth factor-receptor 2 on alveolar septa of DBA/2 and C57BI/6J mice. a) DBA/2 control, b) DBA/2 at 1 month and c) 3 months after smoking. d) C57BI/6J control, e) C57BI/ $6 \mathrm{~J}$ at 1 month and f) 3 months after smoking. Counterstained with haematoxylin Scale bar $=45 \mu \mathrm{m}$.

animals at 1, 3 and 6 months and only two out of eight (25\%) showed a positive PAS staining at 10 months.

In $\mathrm{C} 57 \mathrm{Bl} / 6 \mathrm{~J}$ mice immunohistochemical staining revealed a positive reaction in the airway epithelium for IL-4 at 3 and 6 months associated with a positive staining for IL-13 and MUC5AC (fig. 7a, b and c).

There was no difference between the strains with regard to the degree of deciliation, epithelial injury and repair, as assessed with transmission electron microscopy. Thus, it was possible to observe in the same axial bronchus of a DBA/2 mouse after 3 months of smoke exposure (fig. 8a) all the morphological
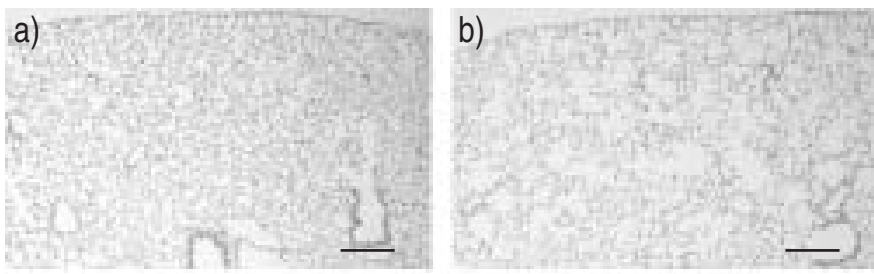

C)
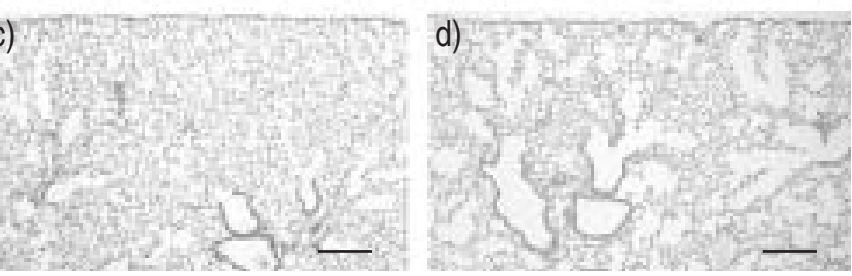

FIGURE 4. Lung parenchyma from an a) air-exposed and b) a smoke-exposed $\mathrm{DBA} / 2$ mouse at 6 months. Lung parenchyma form c) an air-exposed and d) a smoke-exposed C57BI/6J mouse at 6 months. Haematoxylin-eosin stain. Scale $\mathrm{bar}=278 \mu \mathrm{m}$. 

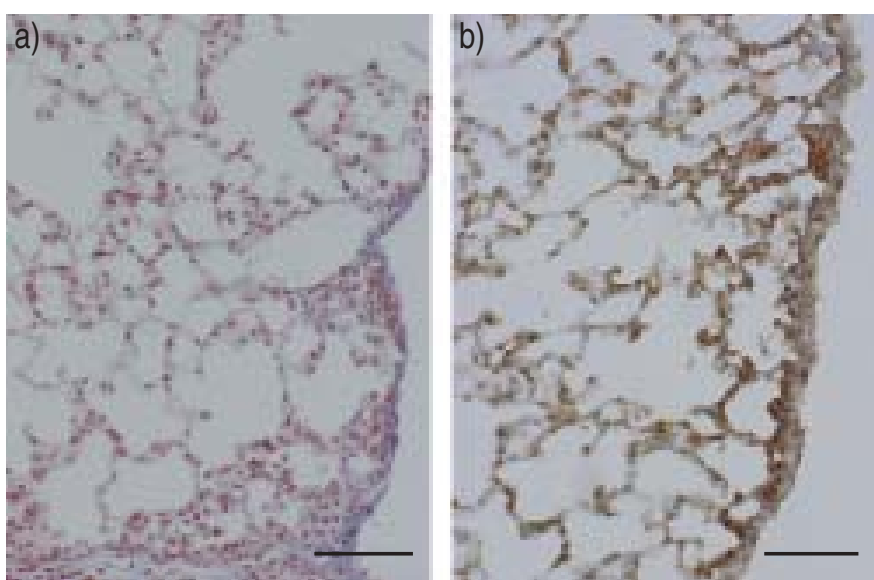

FIGURE 5. Lung parenchyma of a DBA/2 mouse at 6 months after smoke exposure. a) Masson's trichrome stain (scale bar=111 $\mu \mathrm{m}$ ); and b) Immunohistochemical reaction for TGF- $\beta$ counterstained with haematoxylin (scale bar $=65 \mu \mathrm{m})$
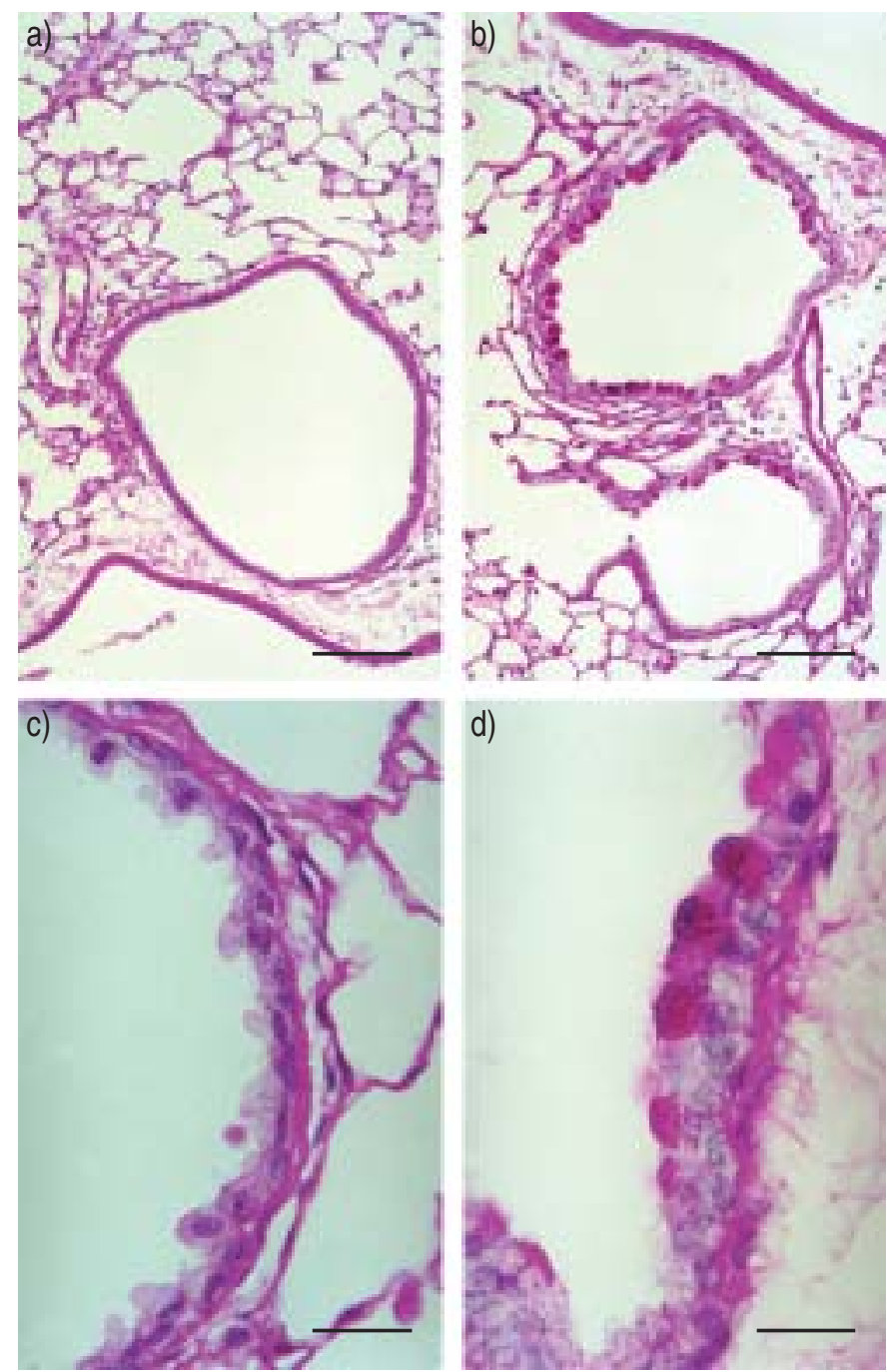

FIGURE 6. Middle size bronchi from an air control $(a, c)$ and a smoke-exposed C57BI/6J (b, d) mouse at 3 months. Periodic acid-Schiff stain. Scale bars: a) and b) $111 \mu \mathrm{m}, \mathrm{c}) 45 \mu \mathrm{m}, \mathrm{d}) 28 \mu \mathrm{m}$.
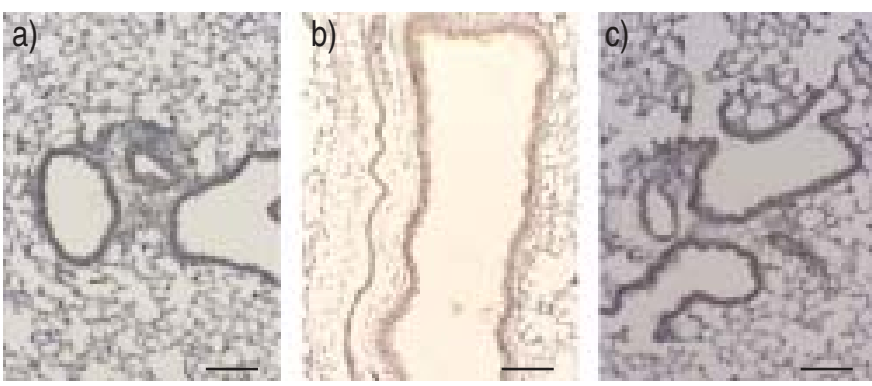

FIGURE 7. Lung parenchyma after 3 months of smoking in a C57BI/6J mouse following immunohistochemical reaction for a) interleukin (IL)-4, b) IL-13 and c) MUC5AC. Counterstained with haematoxylin. Scale bar $=111 \mu \mathrm{m}$

stages characterising the injury and repair process. In particular basal cells that accumulate after epithelial cell detachment (fig. 8c); poorly differentiated cells with short microvilli in the process of covering denuded areas (fig. 8e); and airway epithelium layered by differentiating basal cells (fig. 8d) which have the potential to restore normal epithelial architecture as in figure $8 \mathrm{~b}$. Similar changes were also seen in the C57BL/6J mice.

In the airways of smoke-exposed mice of both strains, the areas of deciliation were interspersed with areas with normal ciliated
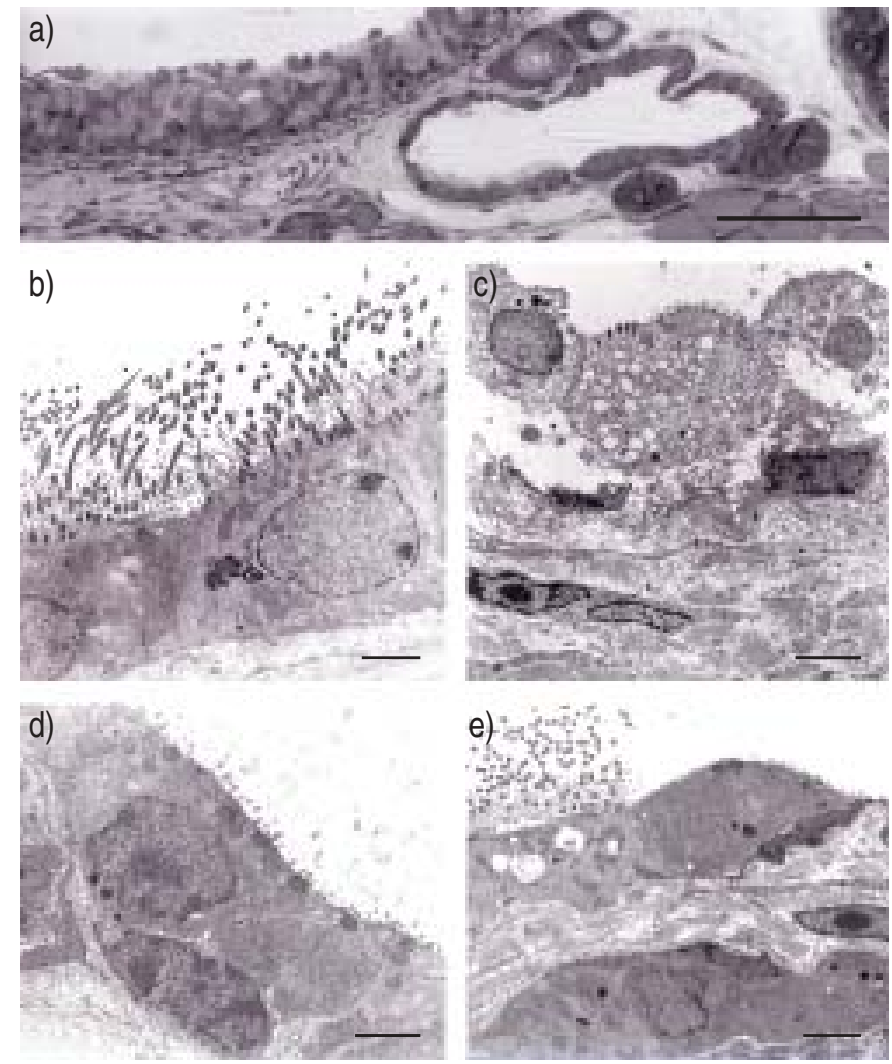

FIGURE 8. a) Axial bronchus of a DBA/2 mouse after 3 months of smoke exposure (toluidine blue). b) Normal epithelial architecture. c) Basal cells that accumulate after epithelial cell detachment. d) Airway epithelium layered by differentiating basal cells. e) Poorly differentiated cells with short microvilli in the process of covering denuded areas (uranyl acetate and lead citrate stain). Scale bars: a) $55 \mu \mathrm{m}$, b) to e) $3.4 \mu \mathrm{m}$. 

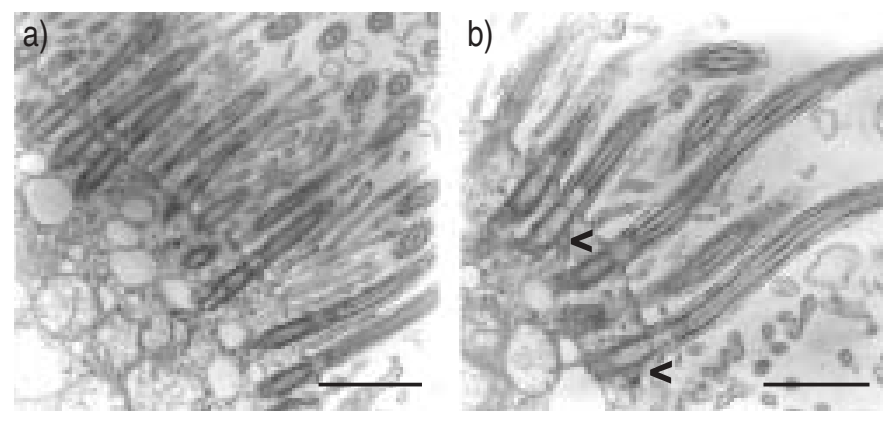

FIGURE 9. Apical portion of a ciliated cell from a) a control and b) a smokeexposed DBA/2 mouse at 3 months. Note in b) a disorientation of the ciliary shafts: two out of five of the ciliary basal bodies show the spurs in the same plane of section and are thus not aligned with the spurs of the other cilia. Uranyl acetate and lead citrate stain. Scale bar $=1 \mu \mathrm{m}$.

epithelium. However, in apparently normal ciliated areas, a disorientation of the ciliary shaft could often be observed. Figure $9 \mathrm{~b}$ shows this lesion in a DBA/ 2 mouse after 3 months of cigarette smoke exposure. For comparison, a ciliated area of an air-exposed DBA/2 mouse is presented in figure 9a.

\section{DISCUSSION}

The main points of the present study are the differences and similarities between the $\mathrm{C} 57 \mathrm{Bl} / 6 \mathrm{~J}$ and DBA/2 strains of mice in their response to chronic cigarette smoke exposure.

Mice of both strains developed patchy emphysema following cigarette smoke. However, in the DBA/2 mice, emphysema developed more rapidly than in the $\mathrm{C} 57 \mathrm{Bl} / 6 \mathrm{~J}$ mice, being already fully developed after 3 months of exposure. Interestingly, in DBA/2 mice between the emphysematous foci the parenchymal network appeared uniformly dilated. This uniform dilation may have contributed to the high $\mathrm{Lm}$ values seen in these mice.

This uniform parenchymal dilation was not seen in the C57Bl/ $6 \mathrm{~J}$ mice. Since C57Bl/6J mice, in comparison to other strains of inbred mice, have lower serum and BALF EIC values $[6,12]$ and are sensitive to cigarette smoke oxidants $[6,13]$, it is reasonable to assume that the development of cigarette smokeinduced emphysema in C57Bl/6 $\mathrm{J}$ mice may be ascribed to these risk factors. The role of the former risk factor is supported by the observation of a positive immunohistochemical reaction for mouse neutrophil elastase on the septa of C57Bl/6J mice coupled with a previous report describing a significant decrease in lung elastin content after cigarette smoke exposure [6]. The patchy distribution of the immunohistological reaction for neutrophil elastase is consistent with the patchy distribution of the emphysematous lesion.

DBA/2 mice have normal EIC values in their BALF. However, they respond to cigarette smoke with a drop in the antioxidant capacity of their BALF [6]. It is thus possible that the emphysema observed in the current study may be related to their sensitivity to oxidants. Chronic oxidative stress may have resulted in emphysema either via a direct effect on lung matrix components and/or via indirect effects, such as inactivation of $\alpha_{1}$-PI [14], and/or sequestration of neutrophils in the lung microvasculature [15]. Both these two latter factors may have contributed to the increase in elastolytic burden. This is also suggested by the fact that, in this strain, a positive immunohistochemical reaction for mouse neutrophil elastase was evident on the alveolar septa and thus may explain the significant decrease in lung elastin content reported after cigarette smoke exposure [6]. Additionally, a role for apoptosis in the development of emphysema in DBA/2 mice cannot be excluded. In fact, numerous apoptotic cells were seen uniformly distributed throughout the parenchyma consistent with the uniform dilation of the air spaces observed in this strain. The appearance of apoptosis was evident at a time when the dilation of the air spaces was not yet fully developed. It may be speculated that apoptotic cell death could be the initiator of emphysema by facilitating the influx of neutrophil elastase into the alveolar septum. Also, in this strain the apoptotic signal after smoke exposure was coupled with a trivial signal for VEGF-R2, which is consistent with previous data obtained in experimental animals and in humans [16, 17]. These latter studies stress a role for apoptosis in the oxidative stress from cigarette smoke. Similarly, in the present study the sensitivity to cigarette smoke oxidants of the DBA/2 mice [6] may have contributed via an apoptotic pathway to the pathogenesis of the dilation of the air spaces and emphysema in this strain. This is also supported by the finding that ICR mice respond to cigarette smoke with an increase of their antioxidant capacity and do not develop emphysema when chronically exposed to cigarette smoke [6].

A clear-cut difference was observed with regard to the fibrotic reaction to cigarette smoke. Whilst the C57Bl/6J mice developed either no fibrosis or only trivial foci of fibrosis, fibrotic areas located subpleurally and/or interspersed in the parenchyma were evident in the DBA/2 mice. The reason for this difference is unknown. However, the fibrotic reaction may be ascribed to a different degree of activation of fibrogenic cytokines, such as TGF- $\beta$, in these two strains.

Following cigarette smoke exposure, the most common changes observed in the airways of both strains of mice at electron microscopy were areas of deciliation. Ciliated cells are end stage cells in that they are easily damaged and are not repaired by direct division. Therefore, replacement involves division and repopulation by other cell types (i.e. basal cells) followed by ciliogenesis. Cells with short microvilli, which often cover the airway epithelium, are considered to represent immature ciliated cells.

In both strains in apparently normal ciliated areas, a disorientation of the ciliary shaft, as visualised by the lack of uniform orientation of the basal foot of the cilia, was also seen. It is believed that the affected cilia do not exhibit coordinated movements [18]. This defect in humans is generally considered to be a primary defect associated with primary ciliary dyskinesia. However, under the experimental conditions of the current study, it appears to be a defect secondary to smoke exposure.

The two strains of mice clearly differed in the development of GCM. Appearance of GCM was a rare event in DBA/2 mice that occurred very late in the cigarette smoke period (at 10 months). In contrast, GCM was present in most C57Bl/6 6 mice at all time points from 1 month onwards following smoke 
exposure. In these mice GCM was associated with a positive immunostaining for MUC5AC. This is a secreted mucin, expressed in goblet cells and at least in man, may potentially contribute to mucus obstruction [19]. Recently, GCM has been found associated with the expression of MUC5AC mRNA and mucin in murine models of allergic asthma [19]. IL-4 and IL-13 are highly effective in inducing mucin synthesis and/or GCM in experimental systems [20-23]. Similarly, central airway expression of IL-4 and IL-13 contribute to mucus hypersecretion and chronic bronchitis in smokers [24]. In the present study, a positive immunohistochemical reaction for IL-4 and IL-13 was seen in the airways of C57Bl/6J mice. IL-4 effects include the recruitment of Th2 cells, which release IL-13. Thus, a chain of events consisting of cigarette smoke, IL-4, IL-13, GCM and mucin secretion may be at the base of the airway changes observed here.

It may well be that the deficit in BALF anti-elastase screen of the C57Bl/6J mice coupled with their sensitivity to oxidants played an important role for development of the airway changes in these mice. Neutrophil elastase stimulates mucin production, secretion and release [25-27]. This effect was recently found to occur via a proteolytic activation of epidermal growth factor receptor signalling cascade involving TGF- $\alpha$ [28]. An additional mechanism involving reactive oxygen species has been put forward [29]. Since DBA/2 mice are sensitive to oxidants, have normal BALF EIC values and do not develop significant GCM, it can be assumed that the proteolytic pathway of MUC5AC activation is more relevant under the experimental conditions of the current study. Studies in this field are in progress in the laboratory of the present authors.

In summary, following chronic exposure to cigarette smoke mice of both strains showed epithelial cell injury and areas of deciliation in their airways. However, appearance of GCM was common in $\mathrm{C} 57 \mathrm{Bl} / 6 \mathrm{~J}$ mice but rare in DBA/2 mice. Since the airway changes of the $\mathrm{C} 57 \mathrm{Bl} / 6 \mathrm{~J}$ mice do not result in morphological evidence of obstruction (air trapping), they are probably not relevant for the pathogenesis of the parenchymal lesions. However, the C57Bl/6J model may be used for addressing pathogenic issues of GCM. With regard to the parenchymal changes, emphysema was present in both strains but developed faster in DBA/2 mice. Additionally, DBA/2 mice developed a uniform parenchymal dilation and foci of fibrotic reaction that were either not present or trivial in C57Bl/6J mice.

In conclusion, strain characteristics (i.e. alpha1-proteinase inhibitor levels, sensitivity to oxidants, and constitutive levels of vascular endothelial growth factor receptor-2) and different phenotypical responses (i.e. apoptosis, and cytokines distribution) may condition different parenchymal and airway changes to cigarette smoke.

\section{REFERENCES}

1 Murray CJ, Lopez AD. Alternative projections mortality and disability by cause: Global Burden of Disease Study. Lancet 1997; 349: 1498-1504.

2 American Thoracic Society. Cigarette smoking and health. Am J Respir Crit Care Med 1996; 153: 861-865.
3 Fletcher C, Peto R. The natural history of chronic airflow obstruction. BMJ 1977; 1: 1645-1648.

4 Sanford AJ, Weir TD, Pare PD. Genetic risk factors for chronic obstructive pulmonary disease. Eur Respir J 1997; 10: 1380-1391.

5 Barnes PJ. Molecular genetic of COPD. Thorax 1999; 554: 245-252.

6 Cavarra E, Bartalesi B, Lucattelli M, et al. Effects of cigarette smoke in mice with different levels of $\alpha 1$ proteinase inhibitor and sensitivity to oxidants. Am J Respir Crit Care Med 2001; 164: 886-890.

7 Thurlbeck WM. Measurement of pulmonary emphysema. Am Rev Respir Dis 1967; 95: 752-764.

8 Thurlbeck WM. Internal surface area of non emphysematous lungs. Am Rev Repir Dis 1967; 95: 765-773.

9 Cavarra E, Martorana PA, Bartalesi B, et al. Genetic deficiency of $\alpha 1-\mathrm{PI}$ in mice influences lung responses to bleomycin. Eur Respir J 2001; 17: 474-480.

10 Pack RJ, Al-Ugaily LH, Morris G. The cells of the tracheobronchial epithelium of the mouse: a quantitative light and electron microscope study. J Anat 1981; 132: 71-84.

11 Lucattelli M, Cavarra E, deSanti MM, Tetley TD, Martorana PA, Lungarella G. Collagen phagocytosis by lung alveolar macrophages in animal models of emphysema. Eur Respir J 2003; 22: 728-734.

12 Gardi C, Cavarra E, Calzoni P, et al. Interstrain variations in content of lysosomal elastase, cathepsin $G$ and their inhibitors. Biochem J 1994; 299: 237-245.

13 Cavarra E, Lucattelli M, Gambelli F, et al. Human SLPI inactivation after cigarette smoke exposure in a new in vivo model of pulmonary oxidative stress. Am J Physiol Lung Cell Mol Physiol 2001; 281: L412-L417.

14 Abboud RT, Fera T, Richter A, Tobona MZ, Johal S. Acute effect of smoking on the functional activity of alpha-1protease inhibitor in bronchoalveolar lavage fluid. Am Rev Respir Dis 1985; 131: 79-85.

15 Drost EM, Selby C, Bridgeman MME, MacNee W. Decreased leukocyte deformability after acute cigarette smoking in humans. Am Rev Respir Dis 1993; 148: 1277-1283.

16 Kasahara Y, Tuder RM, Taraseviciene-Stuart L, et al. Inhibition of VEGF receptors causes lung cell apoptosis and emphysema. J Clin Invest 2000; 106: 1311-1319.

17 Kasahara Y, Tuder RM, Cool CD, Lynch DA, Flores SC, Voelkel NF. Endothelial cell death and decreased expression of vascular endothelial growth factor and vascular endothelial growth factor receptor 2 in emphysema. Am J Respir Crit Care Med 2001; 163: 737-744.

18 Lee RMKW, Forrest JB. Structure and function of cilia. In: Crystal RG, West JB, eds. The Lung: Scientific Foundations, 2nd Edn. Philadelphia, Lippincott-Raven Publishers, 1997; pp. $459-478$.

19 Rose MC, Nickola TJ, Voynow JA. Airway mucus obstruction: mucin glycoproteins, MUC gene regulation and goblet hyperplasia. Am J Respir Cell Mol Biol 2001; 25: 533-537.

20 Alimam MZ, Piazza FM, Selby DM, Letwin N, Huang L, Rose MC. Muc-5/5ac mucin messenger RNA and protein expression is a marker of goblet cell metaplasia in murine airways. Am J Respir Cell Mol Biol 2000; 22: 253-260. 
21 Kibe A, Inoue H, Fukuyama S, et al. Differential regulation by glucocorticoid of interleukin-13-induced eosinophilia, hyperresponsiveness, and goblet cell hyperplasia in mouse airway. Am J Respir Crit Care Med 2003; 167: 50-57.

22 Dabbagh K, Takeyama K, Lee HM, Ueki IF, Lausier JA, Nadel JA. IL-4 induces mucin gene expression and goblet cell metaplasia in vitro and in vivo. J Immunol 1999; 162: 6233-6237.

23 Temann UA, Prasad B, Gallup MW, et al. A novel role for murine IL-4 in vivo; induction of MUC5AC gene expression and mucin hypersecretion. Am J Respir Cell Mol Biol 1997; 16: 471-478.

24 Miotto D, Ruggeri MP, Boschetto P, et al. Interleukin-13 and -4 expression in the central airways of smokers with chronic bronchitis. Eur Respir J 2003; 22: 602-608.

25 Voynow JA, Young LR, Wang Y, Horger T, Rose MC, Fischer BM. Neutrophil elastase increases MUC5AC mRNA and protein expression in respiratory epithelial cells. Am I Physiol Lung Cell Mol Physiol 1999; 276: L835-L843.

26 Christensen TG, Breuer R, Hornstra LJ, Lucey EC, Stone PJ, Snider GL. An ultrastructural study of the response of hamster bronchial epithelium to human neutrophil elastase. Exp Lung Res 1987; 13: 279-297.

27 Lundgren JD, Rieves RD, Mullol J, Logun C, Shelhamer JH. The effect of neutrophil proteinase enzymes on the release of mucus from feline and human airway cultures. Respir Med 1994; 88: 511-518.

28 Kohri K, Ueki IF, Nadel JA. Neutrophil elastase induces mucine production by ligand-dependent epidermal growth factor receptor activation. Am J Physiol Lung Cell Mol Physiol 2002; 283: L67-L75.

29 Fischer BM, Voynow JA. Neutrophil elastase induces MUC5AC gene expression in airway epithelium via a pathway involving reactive oxygen species. Am J Respir Cell Mol Biol 2002; 26: 447-452. 